\title{
Bone augmentation at peri-implant dehiscence defects comparing a synthetic polyethylene glycol hydrogel matrix vs. standard guided bone regeneration techniques
}

\author{
Thoma, Daniel S ; Jung, Ui-Won ; Park, Jin-Young ; Bienz, Stefan P ; Hüsler, Jürg ; Jung, Ronald E
}

\begin{abstract}
OBJECTIVES The aim of the study was to test whether or not the use of a polyethylene glycol (PEG) hydrogel with or without the addition of an arginylglycylaspartic acid (RGD) sequence applied as a matrix in combination with hydroxyapatite/tricalciumphosphate (HA/TCP) results in similar peri-implant bone regeneration as traditional guided bone regeneration procedures. MATERIAL AND METHODS In 12 beagle dogs, implant placement and peri-implant bone regeneration were performed 2 months after tooth extraction in the maxilla. Two standardized box-shaped defects were bilaterally created, and dental implants were placed in the center of the defects with a dehiscence of $4 \mathrm{~mm}$. Four treatment modalities were randomly applied: i)HA/TCP mixed with a synthetic PEG hydrogel, ii)HA/TCP mixed with a synthetic PEG hydrogel supplemented with an RGD sequence, iii)HA/TCP covered with a native collagen membrane (CM), iv)and no bone augmentation (empty). After a healing period of 8 or 16 weeks, micro-CT and histological analyses were performed. RESULTS Histomorphometric analysis revealed a greater relative augmented area for groups with bone augmentation (43.3\%-53.9\% at 8 weeks, $31.2 \%-42.8 \%$ at 16 weeks) compared to empty controls ( $22.9 \%$ at 8 weeks, $1.1 \%$ at 16 weeks). The median amount of newly formed bone was greatest in group CM at both time-points. Regarding the first bone-to-implant contact, $\mathrm{CM}$ was statistically significantly superior to all other groups at 8 weeks. CONCLUSIONS Bone can partially be regenerated at peri-implant buccal dehiscence defects using traditional guided bone regeneration techniques. The use of a PEG hydrogel applied as a matrix mixed with a synthetic bone substitute material might lack a sufficient stability over time for this kind of defect.
\end{abstract}

DOI: https://doi.org/10.1111/clr.12877

Posted at the Zurich Open Repository and Archive, University of Zurich

ZORA URL: https://doi.org/10.5167/uzh-126611

Journal Article

Accepted Version

Originally published at:

Thoma, Daniel S; Jung, Ui-Won; Park, Jin-Young; Bienz, Stefan P; Hüsler, Jürg; Jung, Ronald E (2017). Bone augmentation at peri-implant dehiscence defects comparing a synthetic polyethylene glycol hydrogel matrix vs. standard guided bone regeneration techniques. Clinical Oral Implants Research, 28(7):e76-e83.

DOI: https://doi.org/10.1111/clr.12877 


\section{Bone augmentation at peri-implant dehiscence defects comparing a synthetic polyethylene glycol hydrogel matrix versus standard guided bone regeneration techniques.}

Daniel S. Thoma ${ }^{1}, *$ Ui-Won Jung ${ }^{2}, *$ Jin Young Park ${ }^{2}$, Stefan P. Bienz ${ }^{1}$, Jürg Hüsler ${ }^{1}$, Christoph H.

$$
\text { F. Hämmerle }{ }^{1} \text {, Ronald E. Jung }{ }^{1}
$$

* these authors contributed equally to the study

Key words: dental implants, bone, polyethylene glycols, guided tissue regeneration, bone regeneration, bone substitutes, animal research (all MeSH terms)

Running title: synthetic polyethylene glycol hydrogels for guided bone regeneration

Address for correspondence: $\quad$ Prof. Ui-Won Jung

Department of Periodontology, Research Institute for Periodontal Regeneration, College of Dentistry, Yonsei University, Seoul, South Korea

drjew92@gmail.com

${ }^{1}$ Clinic for Fixed and Removable Prosthodontics and Dental Material Science, University of Zurich, Zurich, Switzerland

${ }^{2}$ Department of Periodontology, Research Institute for Periodontal Regeneration, College of Dentistry, Yonsei University, Seoul, South Korea 


\section{Abstract}

Objectives: to test whether or not the use of a polyethylene glycol (PEG) hydrogel applied as a matrix in combination with hydroxyapatite/tricalciumphosphate (HA/TCP) results in similar periimplant bone regeneration as traditional guided bone regeneration procedures.

Materials and methods: In 12 beagle dogs, implant placement and peri-implant bone regeneration were performed two months after tooth extraction in the maxilla. Two standardized box-shaped defects were created and dental implants were placed in the center of the defects with a dehiscence of $4 \mathrm{~mm}$. Four treatment modalities were randomly applied: HA/TCP mixed with a synthetic PEG hydrogel (PEG), HA/TCP mixed with a synthetic PEG hydrogel supplemented with an RGD sequence (PEG-RGD), HA/TCP covered with a native collagen membrane (CM), no bone augmentation (empty). After a healing period of 8 or 16 weeks, Micro CT and histological analyses were performed.

Results: Histomorphometric analysis revealed a greater relative augmented area (AA/TAA) for groups with bone augmentation (43.3\%-53.9\% at 8 weeks, $31.2 \%-42.8 \%$ at 16 weeks) compared to empty controls (22.9\% at 8 weeks, $1.1 \%$ at 16 weeks). The median amount of newly formed bone was greatest in group $\mathrm{CM}$ at both time points. Regarding the first bone-toimplant contact (fBIC), CM was statistically significantly superior to all other groups at 8 weeks.

Conclusions: Bone can successfully be regenerated at peri-implant buccal dehiscence defects using traditional GBR techniques. The use of a PEG hydrogel applied as a matrix mixed with a synthetic bone substitute material, might lack a sufficient stability over time for this kind of defect. 


\section{Introduction}

Polyethylene glycol (PEG) hydrogel was introduced in dentistry as a biodegradable membrane for guided bone regeneration (GBR) procedures (Jung, et al. 2009, Jung, et al. 2009, Schwarz, et al. 2010, Thoma, et al. 2012, Zambon, et al. 2012). A number of preclinical and clinical trials evaluated a degradable, form-stable PEG formulation with a long-term barrier function (Jung, et al. 2006). This PEG hydrogel demonstrated to be clinical effective in regenerating bone around dental implants similar to a native collagen membrane up to 5 years (Jung, et al. 2015). However, this dense PEG formulation showed a significantly higher exposure rate compared to sites grafted with a collagen membrane (Vierra, et al. 2014). In order to further enhance the clinical handling and to reduce the incidence of postoperative complications, numerous attempts were made to improve cell adhesion of the PEG hydrogel by testing less dense PEG formulations, associated with a reduction in the degradation time (Dahlin, et al. 2014, Halstenberg, et al. 2002, Park, et al. 2004, Park, et al. 2005). Beside the variation of the density, the properties of PEG can be changed by the addition of molecules. Results from a preclinical trial in the rabbit skull demonstrated that the modification of the PEG network with RGD affected soft tissue attachment, bone regeneration, and the host's immunologic reaction (Thoma, et al. 2011). The dense network PEG demonstrated its ability to serve as a barrier membrane with the option of enhancing the soft tissue integration by adding a RGD sequence. It was also speculated that the looser network PEG hydrogel might have the potential to serve as a carrier or stand-alone material for localized bone regeneration and that the addition of RGD might further improve bone formation. In this context, PEG shall be used as a matrix mixed with a bone substitute material, not as a covering membrane (Hanseler, et al. 2012, Jung, et al. 2014). This is supported by a recent preclinical study (Thoma, et al. 2014), demonstrating that the addition of a loose network polyethylene glycol hydrogel to a synthetic bone substitute material (HA/TCP) increased new bone formation compared to the bone substitute material alone at 21 days. It was thereby concluded that the PEG hydrogel matrix might represent an interesting candidate to serve as a matrix for localized bone regeneration with or without the addition of a bone substitute material. It was also concluded that further studies are needed to confirm these results to apply the 
combination of a loose network polyethylene glycol hydrogel and a bone substitute material in more challenging defect models and for guided bone regeneration procedures at implant sites.

The aim of the present study was therefore to test whether or not the use of a polyethylene glycol (PEG) hydrogel applied as a matrix in combination with hydroxyapatite/tricalciumphosphate (HA/TCP) results in similar peri-implant bone regeneration as a control treatment using a membrane covering the same bone substitute (HA/TCP). 


\section{Materials and methods}

The article was written in accordance with the guidelines of the ARRIVE (Animal research: Reporting of in vivo experiments) protocol (Kilkenny, et al. 2010). The protocol was approved by the local ethical committee prior to the beginning of the experiment and the study was performed at the animal laboratory of Yonsei university, Seoul, South Korea.

\section{Animals}

A total of 12 male beagle dogs with a fully developed permanent dentition and healthy periodontal tissues were included in this study. Four weeks prior to the experiment and during the entire study, the dogs were fed with a soft-food diet and water ad libitum. At the beginning, the animals had a mean age of 18 months and a mean weight of $15 \mathrm{~kg}$. All experiments were performed at the animal laboratory accredited by Association for Assessment and Accreditation of Laboratory Animal (AAALAC) international, after ethical approval of the institutional Animal Care and Use Committee regarding animal selection, management, and surgery control.

\section{Guided bone regeneration materials}

The bone substitute material used in this study was a synthetic material consisting of HA/TCP

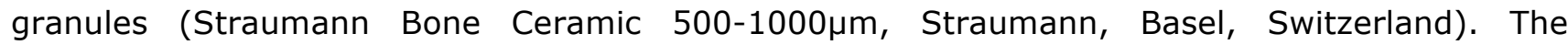
experimental polyethylene glycol hydrogel had a biodegradation of 4 weeks and was applied as a matrix for the bone substitute and RGD. No further membrane coverage was performed in these groups.

\section{Surgical procedures}

The surgical procedures were described in detail in a previous publication (Benic et al. 2015). In brief, all P4 and M1 were extracted in the maxilla. Following a healing period of 2 months, implant placement and peri-implant bone regeneration were performed. For that purpose, dogs were pre-medicated with medetomidine $(0.005 \mathrm{mg} / \mathrm{kg}$, intramusculary) and morphine $(0.5$ $\mathrm{mg} / \mathrm{kg}$ intramusculary). Subsequently, general anesthesia was induced by injection of propofol (2mg/kg intravenously). Isofluorane (1.5-2\%) and $\mathrm{O} 2(100 \%)$ were used as inhalation anesthetics. The animals were monitored routinely and further analgesia was given if necessary within the first days following all surgical procedures. Following a mid-crestal incision between 
the M2 and the canine and two vertical releasing incisions (mesial and distal to the edentulous area) the buccal and lingual alveolar bone plates were exposed. After removing all granulation tissue, the edentulous ridges were slightly flattened to obtain a bucco-oral width of at least 7 $\mathrm{mm}$. Two standardized box-shaped defects were created with a mesio-distal width of $4 \mathrm{~mm}$, bucco-oral depth of $2 \mathrm{~mm}$ and a vertical height of $4 \mathrm{~mm}$ using a straight fissure carbide bur. The defect sites were rinsed with sterile saline to completely remove any residual debris, and the dimensions of the defect were verified by using a periodontal probe. Subsequently, 8-mm-long and 4.1-mm-diameter dental implants (Straumann Bonelevel, Straumann, Basel, Switzerland) were placed in the center of the defects with a final peri-implant dehiscence of $4 \mathrm{~mm}$ (Figure $1 \mathrm{a}$ ). The buccal cortical bone plates were perforated and the following four treatment modalities randomly applied to the peri-implant defects:

i. $\quad$ synthetic particulated bone substitute material (Straumann Bone Ceramic $®$, particle size 0.25-1 mm, Straumann, Basel, Switzerland) mixed with a synthetic PEG hydrogel (Straumann, Basel, Switzerland) (PEG)

ii. $\quad$ synthetic particulated bone substitute material (Straumann Bone Ceramic $®$, particle size 0.25-1 mm, Straumann, Basel, Switzerland) mixed a synthetic PEG hydrogel supplemented with RGD (Straumann, Basel, Switzerland). (PEG-RGD)

iii. Synthetic particulated bone substitute material (Straumann Bone Ceramic $®$, particle size 0.25-1 mm, Straumann, Basel, Switzerland) covered with a non-cross-linked native collagen membrane (Bio-Gide ${ }^{\circledR}$, Geistlich Pharma AG, Wolhusen, Switzerland) (CM)

iv. no further GBR procedure (empty)

In groups PEG and PEG-RGD, the bone substitute material was mixed with the liquid PEG hydrogel and applied to the peri-implant defects (Figure 1b). In group CM, the bone substitute material was applied to the defect and then covered with the collagen membrane, thereby extending $1 \mathrm{~mm}$ beyond the augmented margins (Figure 1c). No further treatment was applied in empty control sites (Figure 1c). Following periostal-releasing incisions, the mucoperiostal flaps were coronally advanced and primary wound closure was accomplished by placing horizontal 
mattress sutures and interrupted sutures (Monosyn ${ }^{\circledR} 4.0$ Glyconate Monofilament, B. Braun Tuttlingen, Germany). Sutures were removed 14 days after surgery (Figure $1 \mathrm{~d}$ ).

After a healing period of 8 weeks $(n=6)$ and 16 weeks $(n=6)$, the animals were painlessly sacrificed with an overdose of sodium pentobarbital 3\%. All surgical sites were macroscopically inspected and any incidences were recorded. The maxillae were block-resected including the surrounding soft tissues.

\section{Micro CT analyses}

A micro-CT (SkyScan 1072, SkyScan, Aartselaar, Belgium) was taken following block resection at a resolution of $35 \mu \mathrm{m}(100 \mathrm{kV}, 100 \mu \mathrm{A})$. The obtained data set was processed and the region of interest reconstructed with three-dimensional (3D) software (OnDemand3D $\AA$, Cybermed, Seoul, Korea). The first bone to implant contact (fBIC) was measured on the lingual (fBIC_ICT) and buccal (fBIC_bCT) side of the implants to the nearest $0.1 \mathrm{~mm}$. Bucco-oral horizontal thickness ( $\mathrm{HT}$ in $\mathrm{mm}$ ) of the mineralized tissue was analyzed at the level of the implant shoulder (HT_0), at $2 \mathrm{~mm}\left(\mathrm{HT} \_2\right)$ and $4 \mathrm{~mm}\left(\mathrm{HT} \_4\right)$ below the implant shoulder (Figure 2a-h).

\section{Histological preparation}

The specimens were fixed in $10 \%$ formalin for 2 weeks. After fixation, samples were grossly bisected at the center of the defect in a mesio-distal direction using the EXAKT cutting system (EXAKT® Apparatebau, Norderstedt, Germany). Specimens were dehydrated using an ascending series of alcohol and embedded in methacrylate-based resin to permit sectioning of bone with the bone graft and dentin in situ. Subsequently, the embedded blocks were polymerized and then fixed to the vacuum head of the EXAKT macro cutter. Sections were prepared with a thickness of approximately $100 \mu \mathrm{m}$. These sections were then ground and polished on the EXAKT micro grinder to a thickness of $15 \mu \mathrm{m}$, mounted on microscope slides and stained with hematoxylin-eosin. 
One experienced investigator who was not aware of the specific experimental conditions performed all analyses. Images were captured with a digital camera (Leica Microsystems digital camera Type DFC 450) connected to a light microscope (Leica Microsystems microscope Type DM6000 B). For histomorphometrical analysis, digital images were evaluated using an image analysis software (Leica Microsystems software LAS V4.3 modules LAS Analysis Bundle and Leica Phase Expert). For each central section, the following variables were assessed:

- $\quad$ total defect area $\left(\mathrm{mm}^{2} ; \mathrm{TAA}\right)$

- regenerated area $\left(\mathrm{mm}^{2} ; \mathrm{AA}\right)$

- $\quad$ percentage of regenerated area within total defect area (\%; AA/TAA) (Figure 3a)

- the percentage of regenerated bone, bone substitute material and non-mineralized tissue within the augmented area (\%) (Figure 3a)

- first bone to implant contact (fBIC), measured from the implant shoulder to the first bone to implant contact on the buccal (fBIC_b) and lingual (fBIC_l) side (Figure 3b)

For TAA and AA, the following volumes were excluded:

- any augmented volume directly superior or lingual to the implant in its axial plane

- any augmented volume inferior to the buccal extension of the inferior border of the defect

- $\quad$ any augmented volume on either side of the defect in its mesio-distal aspect

\section{Statistical analysis}

Descriptive statistics included mean and standard deviation for the marginal bone levels, as well as median with minimum and maximum. These numbers are given for the two different time points, as well as for the four different implant types separately. Multiple mixed models were fitted to the dependent variables for each time point. In these four models, we adjusted for the potentially confounding factors individual dog (as random effect), treatment, side (right or left) and position of implant. Because of the small sample size, one could not investigate complex models with many factors and interaction terms. No correction for the multiple testing of the many dependent variables is applied because of the small study. As primary endpoint we considered the variable \%AA/TAA. The level of significance was set at $p<0.05$. 


\section{Results}

\section{Clinical findings}

All dogs were healthy during the entire study period and neither systemic nor local adverse events were observed and all implants were osseointegrated.

\section{Histomorphometric analysis}

Table 1.A shows the data at 8 weeks, table $1 . B$ shows the data at 16 weeks. At 8 weeks, the median AA/TAA values were greater for groups with bone augmentation (PEG, PEG-RGD, CM) ranging between $43.3 \%$ for $\mathrm{CM}(\min 14.5 \%, \max 72.0 \%)$ and $53.9 \%$ for $\mathrm{PEG}(\min 31.0 \%$, $\max$ $68.2 \%$ ) compared to the empty control group with $22.9 \%$ ( $\min 0.1 \%$, max $48.2 \%$ )(Figure $4 a-d$ ). Between 8 and 16 weeks, the AA/TAA ratio decreased in all groups. At 16 weeks, the median AA/TAA ratios were between $31.2 \%$ for PEG-RGD $(\min 20.0 \%$, $\max 50.0 \%$ ) and $42.8 \%$ for $\mathrm{CM}$ $(\min 21.6 \%, \max 51.2 \%)$ for groups with bone augmentation and $1.1 \%(\min 0.0 \%, \max 8.1 \%)$ for empty controls (Figure 5a-d). The treatment effects were not statistically significant $(p=0.280)$ at 8 weeks, and significant $(p<0.0001)$ at 16 weeks. At 16 weeks also the site had a significant $(p<0.0001)$ impact, but the difference of AA/TAA at the two sites anterior (P4) and posterior (M1) is only about $2 \%$. The median amount of newly formed bone was greatest in group CM $15.8 \%(\min 6.8 \%, \max 24.1 \%)$, lower in the two PEG groups $(6.7 \%(\min 2.1 \%, \max$ $10.9 \%$ ) for PEG and $6.3 \%(\min 3.6 \%, \max 20.2 \%)$ for PEG-RGD) at 8 weeks. Empty control sites rendered a median amount of new bone formation of $7.0 \%(\min 0.7 \%$, $\max 17.6 \%)$. No statistically significant differences were observed between the 4 groups by the mixed linear model $(p=0.108)$. At 16 weeks, the median values were highest for group CM at $17.7 \%$ ( $m$ in $11.0 \%$, max $20.6 \%$ ), whereas in the two PEG groups, the amount of bone was $7.6 \%$ ( $\min 3.9 \%$, $\max 22.3 \%$ ) for PEG and $9.7 \%(\min 3.5 \%, \max 25.5 \%)$ for PEG-RGD, respectively. Empty control sites rendered only a minimal amount of new bone formation with $1.3 \%$ ( $\min 0.0$, $\max$ 8.3\%). Statistically significantly less bone formation was observed in group empty compared to all other groups $(p<0.001,0.018$ and 0.026$)$. In addition, the difference between group CM and 
PEG was statistically significant $(p=0.0388)$.

All groups with bone augmentation (CM, PEG, PEG-RGD) kept the amount of bone substitute material to a similar percentage ranging between $11.3 \%$ ( $\min 0.0 \%$, max $32.8 \%$ ) for group $\mathrm{CM}$ and $18.0 \%$ ( $\min 7.8 \%, \max 32.2 \%$ ) for PEG-RGD at 8 weeks. These numbers decreased slightly to 16 weeks with group CM demonstrating the least amount of bone substitute material $(11.2 \%$, $\min 8.0 \%, \max 20.6 \%$ ). None of the comparisons revealed statistically significant differences between the groups $(p=0.5203$ at 8 weeks and $p=0.7378$ at 16 weeks).

At both sacrifice time-points, the fBIC values were smaller on the lingual side compared to the buccal side. The respective median values on the buccal side ranged between $2.1 \mathrm{~mm}$ ( $\mathrm{min}$ $0.7 \mathrm{~mm}, \max 4.4 \mathrm{~mm})(\mathrm{CM})$ and $3.7 \mathrm{~mm}(\mathrm{~min} 1.3 \mathrm{~mm}$, max $5.2 \mathrm{~mm})$ (PEG-RGD). Group CM was statistically significantly superior to all other groups at 8 weeks $(p=0.002,0.004,0.026)$. At 16 weeks, the median values ranged between $2.5 \mathrm{~mm}(\mathrm{~min} 0.0 \mathrm{~mm}$, $\max 3.8 \mathrm{~mm}$ ) (PEG) and $3.8 \mathrm{~mm}$ (min $1.4 \mathrm{~mm}, \max 4.8 \mathrm{~mm}$ ) (empty) at 16 weeks. PEG and CM were statistically significantly superior compared to empty controls $(p=0.005$ and $<0.001)$.

\section{Micro CT analysis}

Similar to the histological measurements, the fBIC_CT values were smaller on the lingual compared to the buccal side (Figure $2 \mathrm{a}-\mathrm{h}$ ). The median values on the buccal side ranged between $2.0 \mathrm{~mm}(\min 0.9 \mathrm{~mm}, \max 3.5 \mathrm{~mm})(\mathrm{CM})$ and $3.2 \mathrm{~mm}(\mathrm{~min} 2.2 \mathrm{~mm}$, $\max 3.8 \mathrm{~mm})$ (PEGRGD). Similar to the histological measurements, the fBIC_CT values decreased up to 16 weeks for all groups with bone augmentation (PEG, PEG-RGD, CM) and ranged between $1.0 \mathrm{~mm}$ ( $\mathrm{min}$ $0.5 \mathrm{~mm}, \max 4.0 \mathrm{~mm})(\mathrm{CM})$ and $3.5 \mathrm{~mm}(\min 1 \mathrm{~mm}, \max 4.4 \mathrm{~mm})($ empty) at 16 weeks. These differences were not significant at the two time points $(p=0.547$ and 0.104$)$.

The medians of the bucco-oral horizontal thickness of the mineralized tissue at the level of the implant shoulder (HT_0) were 0.00 for all groups, revealing no bone formation up to the implant shoulder at both time-points. At the level $2 \mathrm{~mm}$ below the implant shoulder (HT_2), median values ranged between $0.2 \mathrm{~mm}(\mathrm{~min} 0.0 \mathrm{~mm}$, max $0.6 \mathrm{~mm}$ ) (empty) and $1.8 \mathrm{~mm}$ ( $\mathrm{min} 0.0 \mathrm{~mm}$, $\max 2.2 \mathrm{~mm})(P E G)$ at 8 weeks, which were significantly different $(p=0.044)$. Group PEG 
rendered statistically significantly higher values compared to empty and CM $(p=0.012$ and 0.033). In addition, PEG-RGD was statistically significantly superior compared to empty $(p=0.036)$. The median values decreased in all groups up to 16 weeks, except for group CM (from $0.3 \mathrm{~mm}(\min 0.0 \mathrm{~mm}, \max 1.4 \mathrm{~mm})$ to $0.8 \mathrm{~mm}(\min 0.0 \mathrm{~mm}, \max 1.3 \mathrm{~mm})$. There were no significant differences at $4 \mathrm{~mm}$ below the implant shoulder (HT_4) between the groups $(p=0.526)$, but significant not relevant differences at 8 weeks $(p=0.004)$.

Other than mentioned, none of the differences between the four groups were statistically significant $(p>0.05)$ (Table 1$)$. 


\section{Discussion}

The present preclinical study revealed, based on histomorphometric and micro CT analyses, that bone can be successfully regenerated at peri-implant dehiscence defects using a synthetic bone substitute material in combination with a PEG hydrogel matrix without a barrier membrane or a collagen membrane without significant differences between these groups for most outcome measures. The study also demonstrated that in terms of i) the relative augmented area (\%AA/TAA), the greatest regeneration can be expected at 8 weeks for all groups compared to 16 weeks; ii) PEG hydrogel groups rendered roughly $50 \%$ of newly formed bone with values between $6.3 \%$ and $9.7 \%$ compared to $15.8 \%$ to $17.7 \%$ in the CM group, iii) the first bone to implant contact, none of the groups regenerated bone up to the implant shoulder neither at 8 nor at 16 weeks, CM sites, however, were superior compared to all other groups.

Guided bone regeneration at buccal dehiscence defects is considered to be a successful treatment modality to regenerate bone along the implant surfaces as documented by preclinical and clinical studies using various combinations of materials (Hammerle, et al. 2002). In the present study, the relative augmented area (\%AA/TAA) peaked at 8 weeks with values around $50 \%$ and then decreased up to 16 weeks, predominantly in the PEG hydrogel groups. In contrast to other studies with a similar critical size defect and comparable measuring techniques, relatively low values were obtained for all groups with bone augmentation (Jung, Lee, Park, Thoma, Hammerle \& Jung 2014, Lee, et al. 2015, Thoma, Dard, Halg, Ramel, Hammerle \& Jung 2012). The amount of bone that can be regenerated depends on the surgical technique, the membrane and the membrane supporting bone or bone substitute material used. Empty controls unexpectedly showed new bone formation at 8 weeks, which disappeared again up to 16 weeks. Acute peri-implant defects were used in the present study. These sites have demonstrated to be relatively reactive and might explain bone formation in empty controls at the earlier time-point. Between 8 and 16 weeks, remodeling processes were initiated and some of the newly formed bone might have been lost due to these processes. This also indicates that bone formation at peri-implant defects undergo structural changes during a longer time period. All groups with 
bone augmentation showed bone formation within the total defect area without statistically significant differences between the groups. However, the collagen membrane group revealed $50 \%$ more newly formed bone compared to the PEG groups. PEG hydrogel used in the present study appeared to be degraded rather fast with a negative impact on new bone formation. This is in line with previous preclinical studies using this type of PEG hydrogel with a low network density in different settings (Thoma, Subramani, Weber, Luder, Hammerle \& Jung 2011). In contrast to the classic GBR principle using a membrane, which keeps cells of faster growing adjacent tissues away from migrating into the augmented area, the combination of a bone substitute and a PEG hydrogel matrix follows a different concept (Hanseler, Jung, Jung, Choi, Cho, Hammerle \& Weber 2012, Jung, Lee, Park, Thoma, Hammerle \& Jung 2014). The clinical handling of such a putty material (PEG hydrogel plus bone substitute material) is relatively easy and clinically results in a stable augmented area. Histologic analyses, however, demonstrated that this initially and clinically achieved stability did not persist and bone formation eventually was limited compared to control sites with a collagen membrane.

Ideally, bone regeneration at buccal dehiscence defects aims to regenerate bone up to the implant shoulder. Even though the vertical position of the implants was correct and a submerged healing mode was performed, none of the treatment modalities reached this goal. These results are in line with other studies using the same treatment modality (Lee, Lim, Lee, Hong, Choi \& Jung 2015, Pereira, et al. 2015). One of the explanations could be that bone substitute materials were displaced. In an in vitro study, the displacement of GBR materials was evaluated following wound closure and suturing. The collagen membrane collapses in the coronal portion of the augmented site as long as it is not fixated with pins or a block of bone substitute is used instead of granules (Mir-Mari, et al. 2015). Interestingly, a potentially negative impact of implant surfaces exposed to soft tissues could not be demonstrated. In two clinical studies employing immediate implants with simultaneous GBR, long-term outcomes based on clinical data and CBCT analyses demonstrated stable soft tissues, even though $35 \%$ and $25 \%$ of the implants had no buccal bone plate based on CBCTs (Benic, et al. 2012, Kuchler, et al. 2015). 
The relatively high fBIC values were also reflected by the measurements for the horizontal thickness. The influence of GBR procedures was predominantly visible at a level $2 \mathrm{~mm}$ below the implant shoulder, whereas no bone regenerated more coronally, up to the implant shoulder. The horizontal thickness $4 \mathrm{~mm}$ below the bone crest was defined by the native ridge contour since this was the apical border of the original peri-implant defect. PEG hydrogels reached higher values at a level $2 \mathrm{~mm}$ below the implant shoulder at 8 weeks, but were undergoing greater remodeling process up to 16 weeks compared to the collagen membrane group. Various studies assessed the horizontal thickness following GBR procedures at buccal peri-implant dehiscence defects over time (Schneider, et al. 2014) (Jung, Halg, Thoma \& Hammerle 2009, Zitzmann, et al. 1997). All data are based on clinical measurements and demonstrate a decrease of the augmented area of approximately $1 \mathrm{~mm}$ over the course of 6 months. These clinical data also demonstrate that, during the healing phase, augmented bone/bone substitute materials are remodeled and that the horizontal thickness of the bone thereby decreases.

Previous experimental studies showed early bone formation when RGD was applied on implant surfaces (Germanier, et al. 2006) and improved bone formation as well as more intimate contact to soft tissues when applied in combination with PEG hydrogels (Schneider, et al. 2011, Thoma, Subramani, Weber, Luder, Hammerle \& Jung 2011). The amount of newly formed bone in the present study was higher with the addition of RGD, but did not reach statistically significant differences. The same applies for all other outcomes measures that were not significantly affected by RGD. Most of the positive effects of RGD found in other studies were measured at earlier time-points. Therefore, the influence of RGD might not be measurable at later follow-up time-points such as 8 or 16 weeks like in the present study.

Comparing both PEG groups with the collagen membrane in terms of guided bone regeneration, few differences were observed. In brief, CM showed better results in terms of the first bone to implant contact and more bone formation at the later time-point. The PEG formulation with a low density might be suitable as a matrix for bone substitute materials and demonstrated a good clinical applicability and stability of the augmented area prior to wound closure. The relatively 
fast degradation as reported in previous studies, might, however, have a negative impact on new bone formation and long-term space-maintenance (Thoma, Subramani, Weber, Luder, Hammerle \& Jung 2011). 


\section{Conclusions}

Bone can be regenerated successfully at peri-implant buccal dehiscence defects in dogs using a combination of a synthetic bone substitute and a collagen membrane or a PEG hydrogel matrix. Minimal differences were observed between the groups with bone augmentation for most outcome measures. The CM group, however, demonstrated to be superior in terms of regenerated bone and the first bone-to-implant contact. The use of a PEG hydrogel with or without RGD, applied as a matrix mixed with a synthetic bone substitute material, might lack a sufficient stability over time for this kind of peri-implant defect. 


\section{Acknowledgements and conflict of interest}

The help and support of Dr. In-Kyeong Lee and Sora Yoon at the Department of Periodontology, Yonsei University is greatly appreciated. The authors would also like to address gratitude to Ms. Sonja Hitz, Clinic of Fixed and Removable Prosthodontics and Dental Material Science, University of Zurich for the histomorphometric analysis of the slides. The study was supported by the Clinic for Fixed and Removable Prosthodontics and Dental Material Science, University of Zurich, Switzerland, and by the basic science research program through the National Research Foundation of Korea funded by the Ministry of Education (NRF-2014R1A1A1A05002953). The PEG hydrogels and the HA/TCP materials were provided by Institut Straumann AG, Basel, Switzerland. The authors report no conflicts of interests. 
Table 1. Descriptive statistics with means, standard deviations and medians of histomorphometric measurements within the region of interest and micro-CT analysis by matrix/membrane A. at 8 weeks; B. at 16 weeks; SD=standard deviation. PEG = synthetic particulated bone substitute mixed a synthetic PEG hydrogel; PEG-RGD = synthetic particulated bone substitute material mixed a synthetic PEG hydrogel supplemented with RGD; CM = synthetic particulated bone substitute material covered with a non-cross-linked native collagen membrane; empty = no further GBR procedure.

Figure 1a Implant placed after flap elevation and creation of the bony defects at the sites M1 (left) and P4 (right).

Figure 1b. Material application of PEG-RGD at P4 (left) and PEG at M1 (right). PEG = synthetic particulated bone substitute mixed a synthetic PEG hydrogel; PEG-RGD = synthetic particulated bone substitute material mixed a synthetic PEG hydrogel supplemented with RGD.

Figure 1c Material application of $\mathrm{CM}$ at $\mathrm{P} 4$ (left) and $\mathrm{M} 1$ remaining empty control (right). $\mathrm{CM}=$ synthetic particulated bone substitute material covered with a non-cross-linked native collagen membrane.

Figure 1d Suture removal at 14 days.

Figure 2a-d Micro-CT at 8 weeks for PEG (2a), PEG-RGD (2b), CM (2c), empty control (2d). PEG = synthetic particulated bone substitute mixed a synthetic PEG hydrogel; PEG-RGD = synthetic particulated bone substitute material mixed a synthetic PEG hydrogel supplemented with RGD; $\mathrm{CM}=$ synthetic particulated bone substitute material covered with a non-cross-linked native collagen membrane. Micro-CT measurements of buccal and lingual first bone to implant contact (fBIC_CT) are shown in blue. Horizontal thickness measurements (red) at the buccal implant shoulder (HT_0) and at $2 \mathrm{~mm}$ (HT_2) respectively $4 \mathrm{~mm}$ (HT_4) below the implant shoulder. Green measurements determine the height at which the HT measurements were performed.

Figure 2e-h Micro-CT at 16 weeks for PEG (2e), PEG-RGD (2f), CM (2g), empty control (2h). PEG = synthetic particulated bone substitute mixed a synthetic PEG hydrogel; PEG-RGD = synthetic particulated bone substitute material mixed a synthetic PEG hydrogel supplemented with RGD; $C M$ = synthetic particulated bone substitute material covered with a non-cross-linked 
native collagen membrane. Micro-CT measurements of buccal and lingual first bone to implant contact (fBIC_CT) are shown in blue. Horizontal thickness measurements (red) at the buccal implant shoulder (HT_0) and at $2 \mathrm{~mm}$ (HT_2) respectively $4 \mathrm{~mm}$ (HT_4) below the implant shoulder. Green measurements determine the height at which the HT measurements were performed.

Figure 3a Histomorphometric analysis within the defined region of interest (ROI).

Figure 3b Histologic evaluation of the first bone to implant contact on the buccal und lingual aspect of the implant.

Figure 4a-d Histology at 8 weeks for PEG (3a), PEG-RGD (3b), CM (3c), empty control (3d). PEG = synthetic particulated bone substitute mixed a synthetic PEG hydrogel; PEG-RGD = synthetic particulated bone substitute material mixed a synthetic PEG hydrogel supplemented with RGD; $C M$ = synthetic particulated bone substitute material covered with a non-cross-linked native collagen membrane. $\mathrm{BS}=$ bone substitute, $\mathrm{B}=$ bone, $\mathrm{NB}=$ new bone

Figure 5a-d Histology at 16 weeks for PEG (4a), PEG-RGD (4b), CM (4c), empty control (4d). PEG = synthetic particulated bone substitute mixed a synthetic PEG hydrogel; PEG-RGD = synthetic particulated bone substitute material mixed a synthetic PEG hydrogel supplemented with RGD; $C M$ = synthetic particulated bone substitute material covered with a non-cross-linked native collagen membrane. $\mathrm{BS}=$ bone substitute, $\mathrm{B}=$ bone, $\mathrm{NB}=$ new bone 


\section{References}

Benic, G. I., Mokti, M., Chen, C. J., Weber, H. P., Hammerle, C. H. \& Gallucci, G. O. (2012) Dimensions of buccal bone and mucosa at immediately placed implants after 7 years: A clinical and cone beam computed tomography study. Clinical Oral Implants Research 23: 560-566. Dahlin, C., Johansson, A., Hoffman, M. \& Molenberg, A. (2014) Early biocompatibility of poly (ethylene glycol) hydrogel barrier materials for guided bone regeneration. An in vitro study using human gingival fibroblasts (hgf-1). Clinical Oral Implants Research 25: 16-20. Germanier, Y., Tosatti, S., Broggini, N., Textor, M. \& Buser, D. (2006) Enhanced bone apposition around biofunctionalized sandblasted and acid-etched titanium implant surfaces. A histomorphometric study in miniature pigs. Clinical Oral Implants Research 17: 251-257. Halstenberg, S., Panitch, A., Rizzi, S., Hall, H. \& Hubbell, J. A. (2002) Biologically engineered protein-graft-poly(ethylene glycol) hydrogels: A cell adhesive and plasmin-degradable biosynthetic material for tissue repair. Biomacromolecules 3: 710-723. Hammerle, C. H., Jung, R. E. \& Feloutzis, A. (2002) A systematic review of the survival of implants in bone sites augmented with barrier membranes (guided bone regeneration) in partially edentulous patients. Journal of Clinical Periodontology 29 Suppl 3: 226-231; discussion 232-223.

Hanseler, P., Jung, U. W., Jung, R. E., Choi, K. H., Cho, K. S., Hammerle, C. H. \& Weber, F. E. (2012) Analysis of hydrolyzable polyethylene glycol hydrogels and deproteinized bone mineral as delivery systems for glycosylated and non-glycosylated bone morphogenetic protein-2. Acta biomaterialia 8: 116-123.

Jung, R. E., Benic, G. I., Scherrer, D. \& Hammerle, C. H. (2015) Cone beam computed tomography evaluation of regenerated buccal bone 5 years after simultaneous implant placement and guided bone regeneration procedures--a randomized, controlled clinical trial. Clinical Oral Implants Research 26: 28-34.

Jung, R. E., Halg, G. A., Thoma, D. S. \& Hammerle, C. H. (2009) A randomized, controlled clinical trial to evaluate a new membrane for guided bone regeneration around dental implants. Clinical Oral Implants Research 20: 162-168. 
Jung, R. E., Lecloux, G., Rompen, E., Ramel, C. F., Buser, D. \& Hammerle, C. H. (2009) A feasibility study evaluating an in situ formed synthetic biodegradable membrane for guided bone regeneration in dogs. Clinical Oral Implants Research 20: 151-161.

Jung, R. E., Zwahlen, R., Weber, F. E., Molenberg, A., van Lenthe, G. H. \& Hammerle, C. H. (2006) Evaluation of an in situ formed synthetic hydrogel as a biodegradable membrane for guided bone regeneration. Clinical Oral Implants Research 17: 426-433.

Jung, U. W., Lee, I. K., Park, J. Y., Thoma, D. S., Hammerle, C. H. \& Jung, R. E. (2014) The efficacy of bmp-2 preloaded on bone substitute or hydrogel for bone regeneration at peri-implant defects in dogs. Clinical Oral Implants Research.

Kilkenny, C., Browne, W., Cuthill, I. C., Emerson, M., Altman, D. G. \& Group, N. C. R. R. G. W. (2010) Animal research: Reporting in vivo experiments: The arrive guidelines. J Gene Med 12: 561-563.

Kuchler, U., Chappuis, V., Gruber, R., Lang, N. P. \& Salvi, G. E. (2015) Immediate implant placement with simultaneous guided bone regeneration in the esthetic zone: 10-year clinical and radiographic outcomes. Clinical Oral Implants Research.

Lee, I. K., Lim, H. C., Lee, J. S., Hong, J. Y., Choi, S. H. \& Jung, U. W. (2015) Layered approach with autogenous bone and bone substitute for ridge augmentation on implant dehiscence defects in dogs. Clinical Oral Implants Research.

Mir-Mari, J., Wui, H., Jung, R. E., Hammerle, C. H. \& Benic, G. I. (2015) Influence of blinded wound closure on the volume stability of different gbr materials: An in vitro cone-beam computed tomographic examination. Clinical Oral Implants Research.

Park, K. H., Kim, M. H., Park, S. H., Lee, H. J., Kim, I. K. \& Chung, H. M. (2004) Synthesis of arg-gly-asp (rgd) sequence conjugated thermo-reversible gel via the peg spacer arm as an extracellular matrix for a pheochromocytoma cell (pc12) culture. Bioscience, Biotechnology, and Biochemistry 68: 2224-2229.

Park, K. H., Na, K. \& Chung, H. M. (2005) Enhancement of the adhesion of fibroblasts by peptide containing an arg-gly-asp sequence with poly(ethylene glycol) into a thermo-reversible hydrogel as a synthetic extracellular matrix. Biotechnol Lett 27: 227-231. 
Pereira, F. P., De Santis, E., Hochuli-Vieira, E., de Souza Faco, E. F., Pantani, F., Salata, L. A. \& Botticelli, D. (2015) Deproteinized bovine bone mineral or autologous bone at dehiscence type defects at implants installed immediately into extraction sockets: An experimental study in dogs. Clinical Implant Dentistry and Related Research.

Schneider, D., Weber, F. E., Grunder, U., Andreoni, C., Burkhardt, R. \& Jung, R. E. (2014) A randomized controlled clinical multicenter trial comparing the clinical and histological performance of a new, modified polylactide-co-glycolide acid membrane to an expanded polytetrafluorethylene membrane in guided bone regeneration procedures. Clinical Oral Implants Research 25: 150-158.

Schneider, D., Weber, F. E., Hammerle, C. H., Feloutzis, A. \& Jung, R. E. (2011) Bone regeneration using a synthetic matrix containing enamel matrix derivate. Clinical Oral Implants Research 22: 214-222.

Schwarz, F., Jung, R. E., Fienitz, T., Wieland, M., Becker, J. \& Sager, M. (2010) Impact of guided bone regeneration and defect dimension on wound healing at chemically modified hydrophilic titanium implant surfaces: An experimental study in dogs. Journal of Clinical Periodontology 37: 474-485.

Thoma, D. S., Dard, M. M., Halg, G. A., Ramel, C. F., Hammerle, C. H. \& Jung, R. E. (2012) Evaluation of a biodegradable synthetic hydrogel used as a guided bone regeneration membrane: An experimental study in dogs. Clinical Oral Implants Research 23: 160-168.

Thoma, D. S., Schneider, D., Mir-Mari, J., Hammerle, C. H., Gemperli, A. C., Molenberg, A., Dard, M. \& Jung, R. E. (2014) Biodegradation and bone formation of various polyethylene glycol hydrogels in acute and chronic sites in mini-pigs. Clinical Oral Implants Research 25: 511-521. Thoma, D. S., Subramani, K., Weber, F. E., Luder, H. U., Hammerle, C. H. \& Jung, R. E. (2011) Biodegradation, soft and hard tissue integration of various polyethylene glycol hydrogels: A histomorphometric study in rabbits. Clinical Oral Implants Research 22: 1247-1254. Vierra, M., Mau, L. P., Huynh-Ba, G., Schoolfield, J. \& Cochran, D. L. (2014) A lateral ridge augmentation study to evaluate a synthetic membrane for guided bone regeneration: An experiment in the canine mandible. Clinical Oral Implants Research. 
Zambon, R., Mardas, N., Horvath, A., Petrie, A., Dard, M. \& Donos, N. (2012) The effect of loading in regenerated bone in dehiscence defects following a combined approach of bone grafting and gbr. Clinical Oral Implants Research 23: 591-601.

Zitzmann, N. U., Naef, R. \& Scharer, P. (1997) Resorbable versus nonresorbable membranes in combination with bio-oss for guided bone regeneration. International Journal of Oral and Maxillofacial Implants 12: 844-852. 


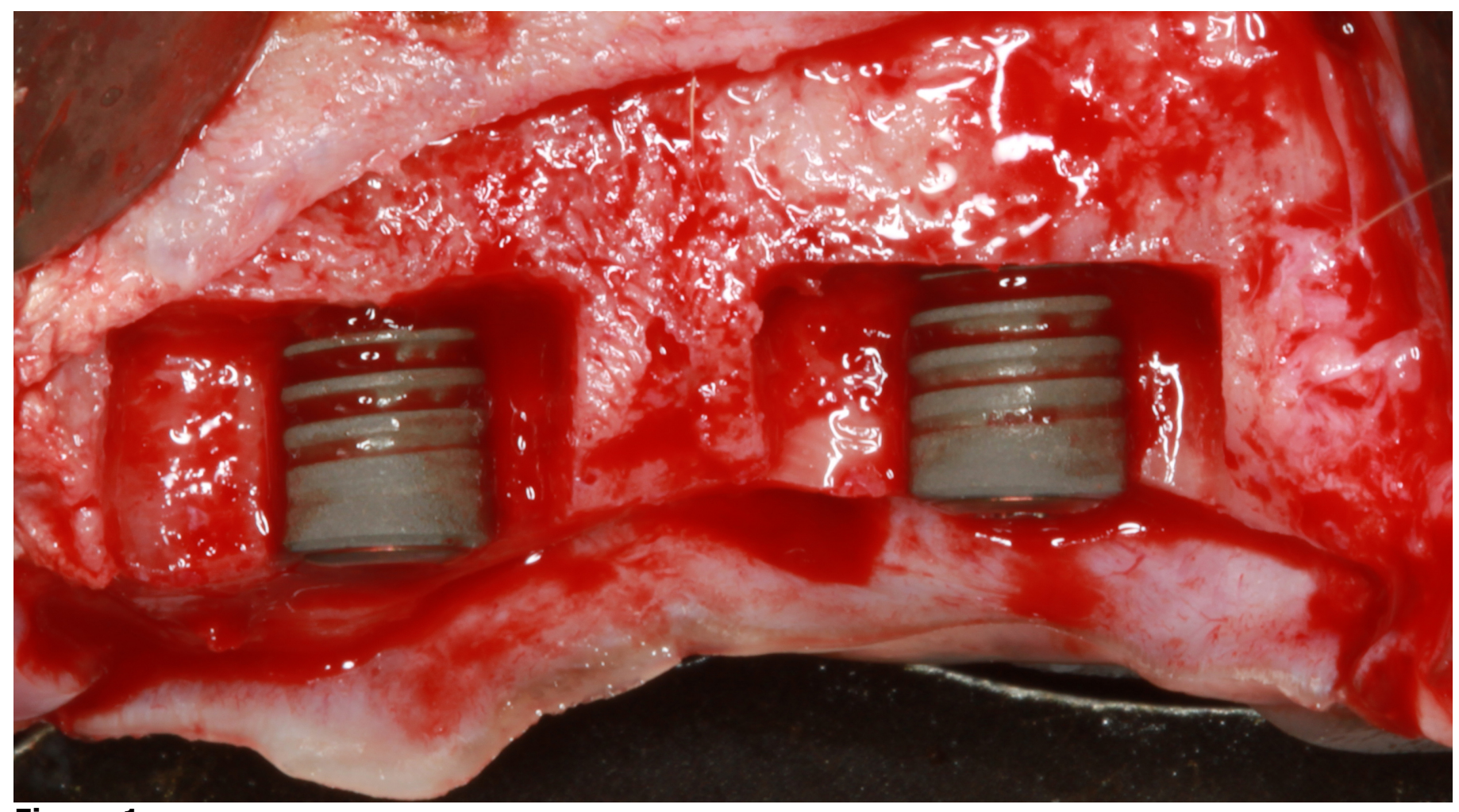

Figure 1a

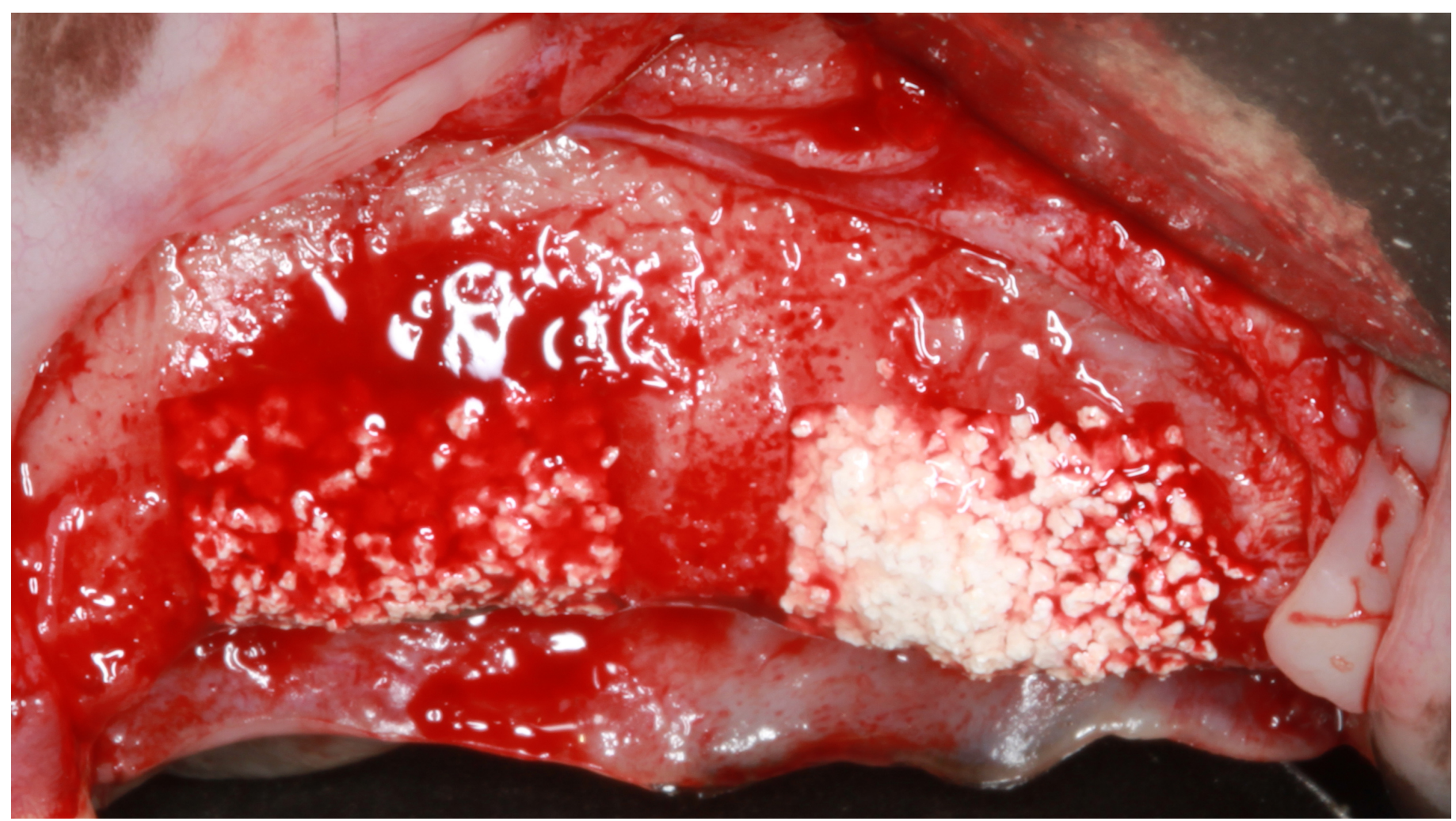

Figure 1b 


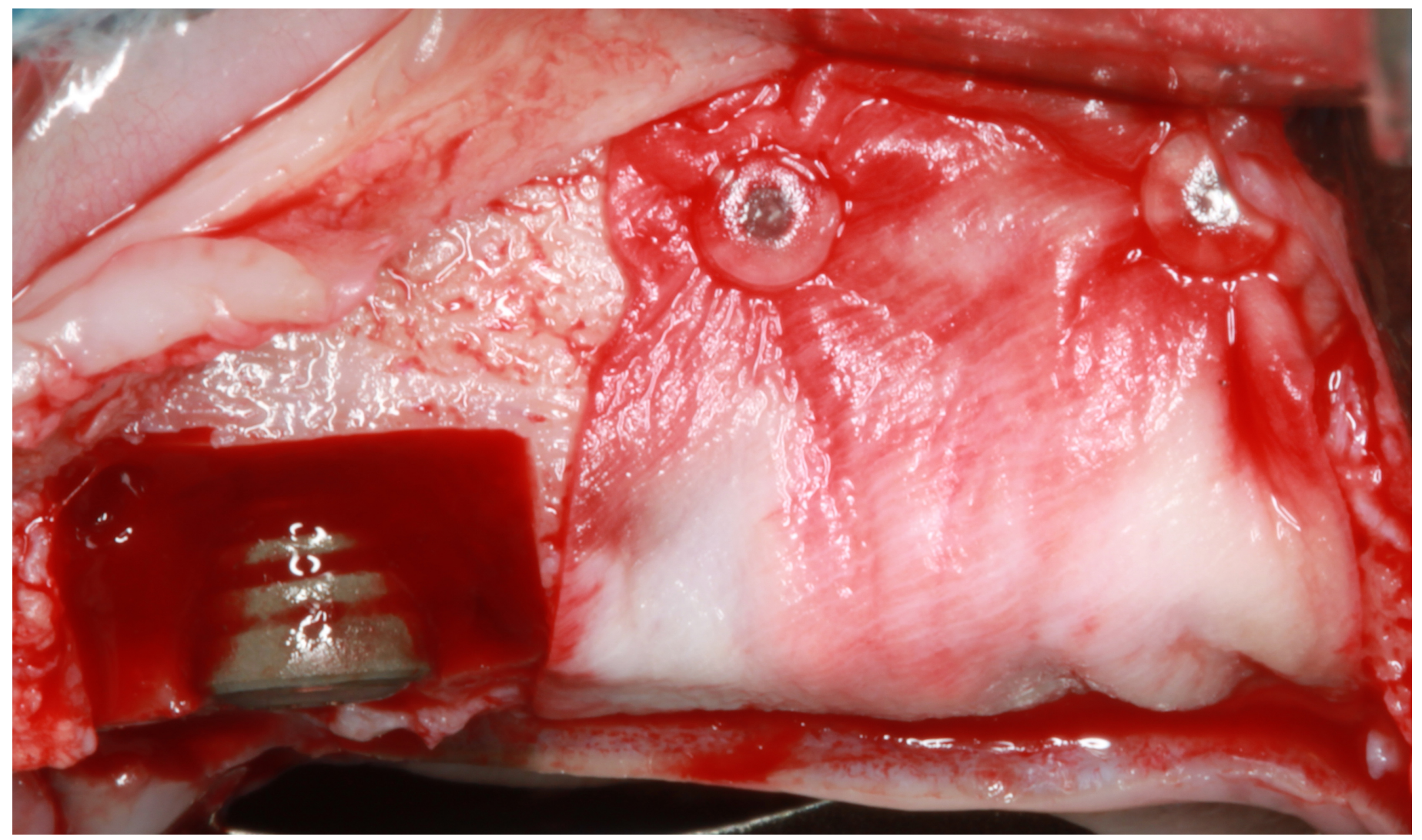

Figure 1c

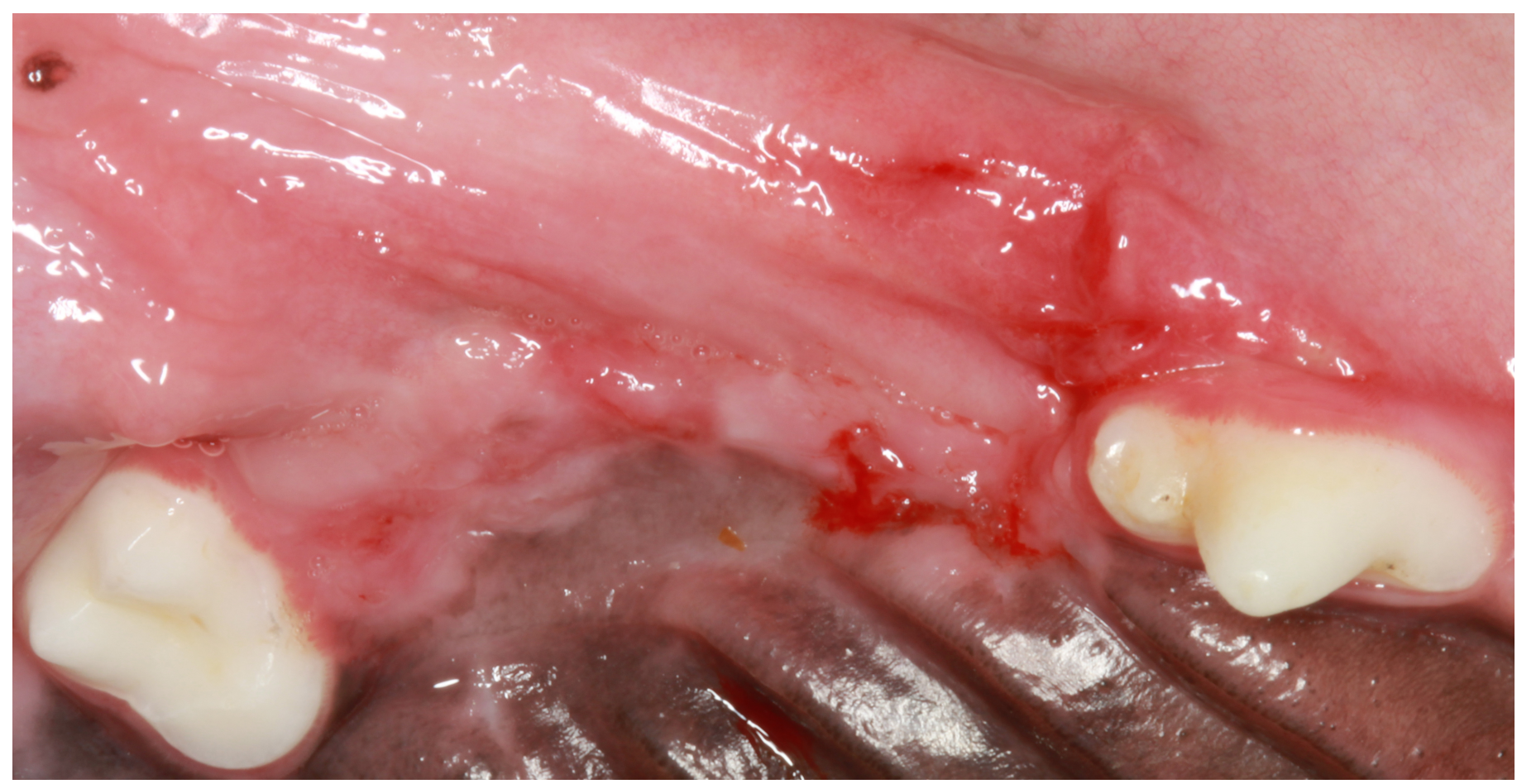

Figure 1d 

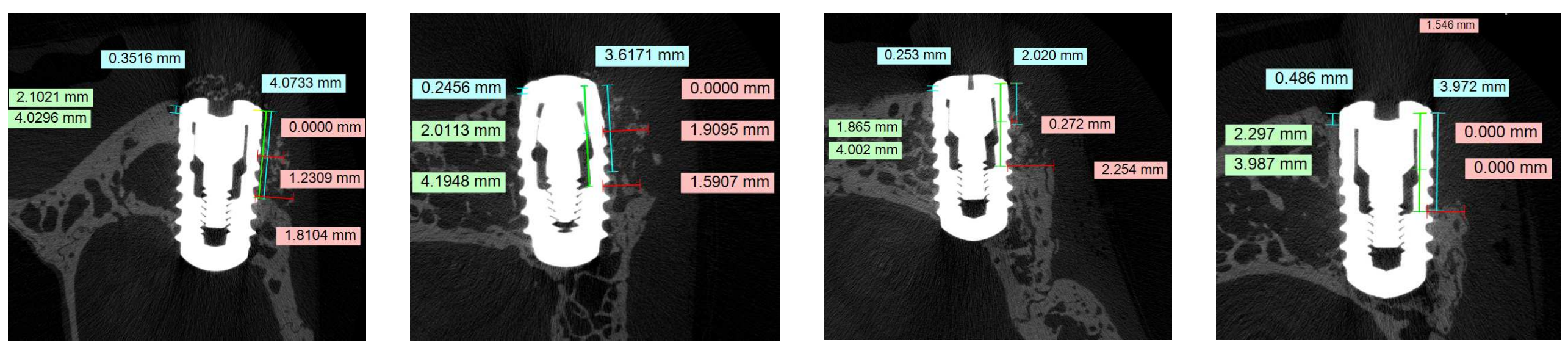

Figure 2a-d
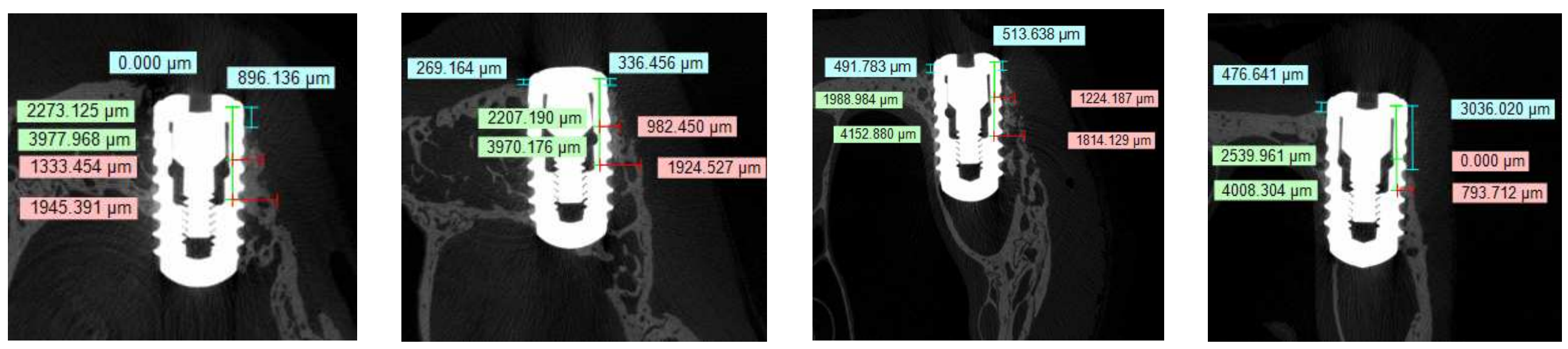

\section{Figure 2e-h}




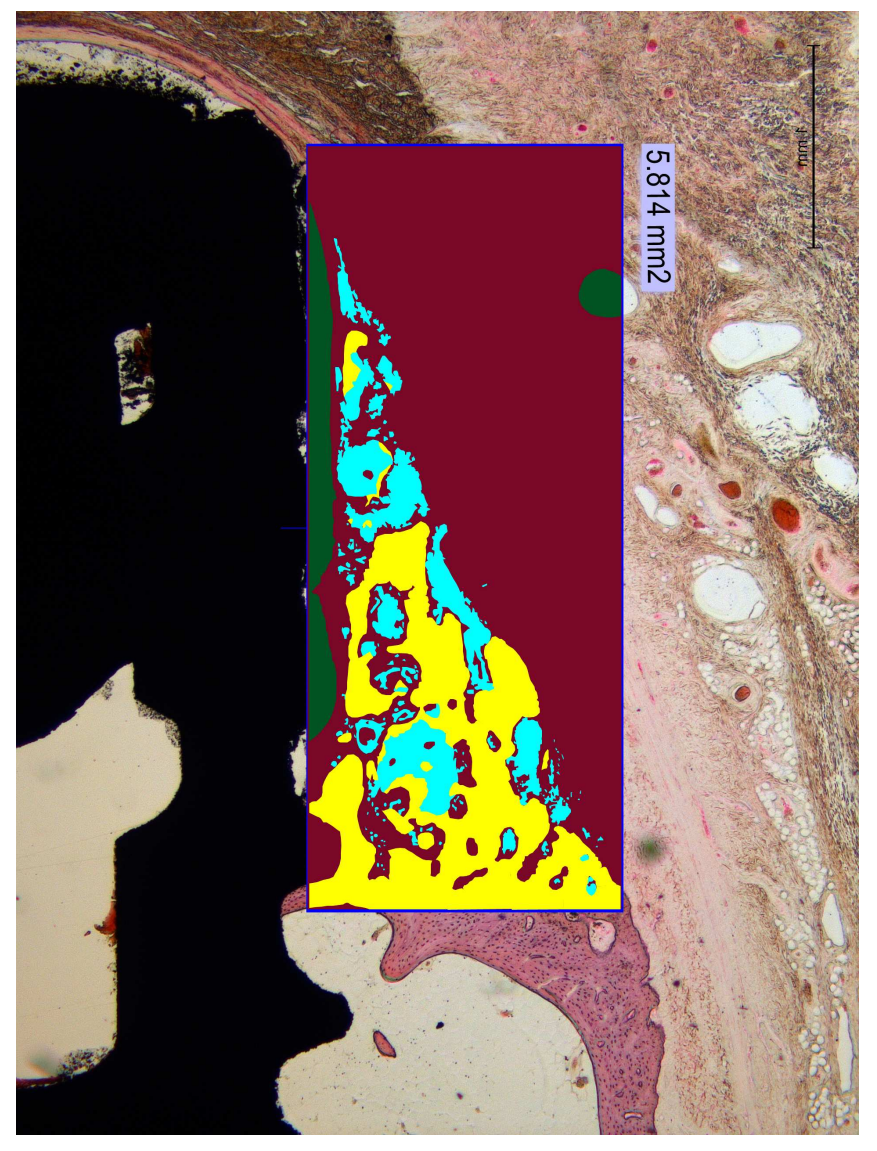

Figure $3 a$

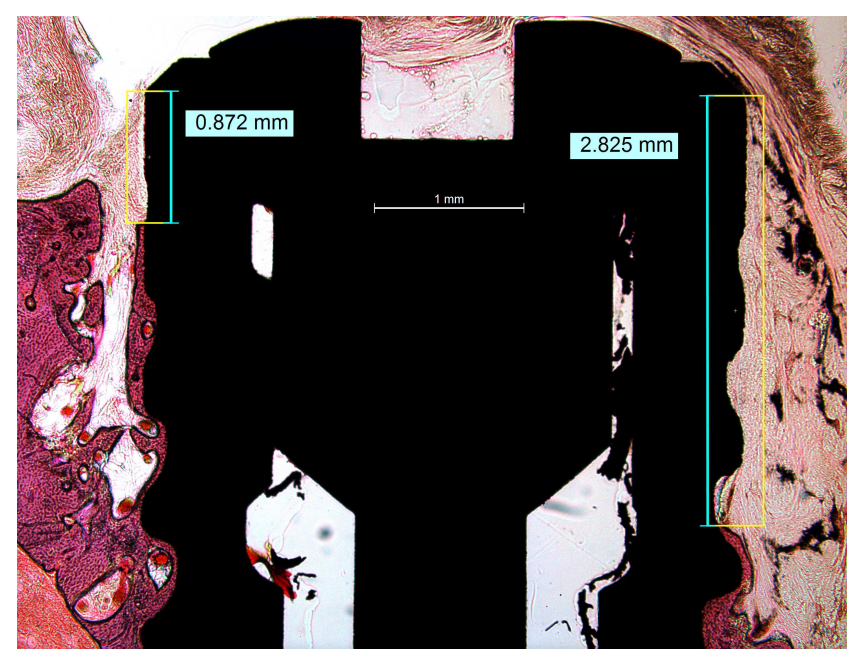

Figure $\mathbf{3 b}$ 
Table $1 \mathrm{~A}$

\begin{tabular}{|c|c|c|c|c|c|c|c|c|c|c|c|c|c|c|c|c|c|}
\hline \multirow{4}{*}{$\begin{array}{l} \\
\text { Histo- } \\
\text { morpho- } \\
\text { metric }\end{array}$} & \multirow[t]{2}{*}{ Variable } & \multirow{2}{*}{\multicolumn{4}{|c|}{ PEG }} & \multirow{2}{*}{\multicolumn{4}{|c|}{$\begin{array}{l}\text { PEG-RGD } \\
\end{array}$}} & \multicolumn{4}{|c|}{$\mathrm{CM}$} & \multirow{2}{*}{\multicolumn{4}{|c|}{ empty }} \\
\hline & & & & & & & & & & $n$ & Mean \pm SD & Median & Min;Max & & & & Min;Max \\
\hline & AA/TAA & 6 & $\begin{array}{l}52.6 \% \pm \\
12.9 \%\end{array}$ & $53.9 \%$ & $\begin{array}{l}31.0 \% \\
68.2 \%\end{array}$ & 6 & $\begin{array}{l}49.7 \% \pm \\
16.8 \%\end{array}$ & $51.2 \%$ & $\begin{array}{l}25.8 \% \\
74.0 \%\end{array}$ & 6 & $\begin{array}{l}46.0 \% \pm \\
21.7 \%\end{array}$ & $43.3 \%$ & $\begin{array}{l}14.5 \% ; \\
72.0 \%\end{array}$ & 5 & $\begin{array}{l}23.8 \% \pm \\
22.0 \% \\
\end{array}$ & $22.9 \%$ & $\begin{array}{l}0.1 \% ; \\
48.2 \%\end{array}$ \\
\hline & $\begin{array}{l}\text { Newly formed } \\
\text { bone }\end{array}$ & 6 & $\begin{array}{l}6.6 \% \pm \\
3.1 \% \\
\end{array}$ & $6.7 \%$ & $\begin{array}{l}2.1 \% \\
10.9 \% \\
\end{array}$ & 6 & $\begin{array}{l}8.9 \% \pm \\
6.7 \%\end{array}$ & $6.3 \%$ & $\begin{array}{l}3.6 \% \\
20.2 \% \\
\end{array}$ & 6 & $\begin{array}{l}15.0 \% \pm \\
7.1 \% \\
\end{array}$ & $15.8 \%$ & $\begin{array}{l}6.8 \% \\
24.1 \% \\
\end{array}$ & 5 & \begin{tabular}{|l}
$7.5 \% \pm$ \\
$6.4 \%$ \\
\end{tabular} & $7.0 \%$ & $\begin{array}{l}0.7 \% \\
17.6 \% \\
\end{array}$ \\
\hline \multirow{3}{*}{ analysis } & $\begin{array}{l}\text { Bone } \\
\text { substitute }\end{array}$ & 6 & $\begin{array}{l}15.0 \% \pm \\
7.2 \% \\
\end{array}$ & $16.9 \%$ & $\begin{array}{l}3.5 \% \\
24.4 \% \\
\end{array}$ & 6 & $\begin{array}{l}20.1 \% \pm \\
9.8 \% \\
\end{array}$ & $18.0 \%$ & $\begin{array}{l}7.8 \% \\
32.2 \% \\
\end{array}$ & 6 & $\begin{array}{l}13.9 \% \pm \\
11.9 \%\end{array}$ & $11.3 \%$ & $\begin{array}{l}0.0 \% \\
32.8 \% \\
\end{array}$ & 5 & \begin{tabular}{|l}
$0.0 \% \pm$ \\
$0.0 \%$ \\
\end{tabular} & $0.0 \%$ & $\begin{array}{l}0.0 \% ; \\
0.0 \%\end{array}$ \\
\hline & fBIC_buccal & 6 & $\begin{array}{l}3.7 \mathrm{~mm} \pm \\
0.4 \mathrm{~mm}\end{array}$ & $3.7 \mathrm{~mm}$ & $\begin{array}{l}3.0 \mathrm{~mm} \\
4.0 \mathrm{~mm}\end{array}$ & 6 & $\begin{array}{l}3.6 \mathrm{~mm} \pm \\
1.3 \mathrm{~mm}\end{array}$ & $3.7 \mathrm{~mm}$ & $\begin{array}{l}1.3 \mathrm{~mm} \\
5.2 \mathrm{~mm} \\
\end{array}$ & 6 & $\begin{array}{l}2.4 \mathrm{~mm} \pm \\
1.5 \mathrm{~mm}\end{array}$ & $2.1 \mathrm{~mm}$ & $\begin{array}{l}0.7 \mathrm{~mm} \\
4.4 \mathrm{~mm}\end{array}$ & 6 & $\begin{array}{l}3.0 \mathrm{~mm} \pm \\
1.1 \mathrm{~mm} \\
\end{array}$ & $3.2 \mathrm{~mm}$ & $\begin{array}{l}1.2 \mathrm{~mm} ; \\
4.2 \mathrm{~mm}\end{array}$ \\
\hline & fBIC_lingual & 6 & $\begin{array}{l}0.3 \mathrm{~mm} \pm \\
0.2 \mathrm{~mm}\end{array}$ & $0.3 \mathrm{~mm}$ & $\begin{array}{l}0.0 \mathrm{~mm} \\
0.5 \mathrm{~mm}\end{array}$ & 6 & $\begin{array}{l}0.6 \mathrm{~mm} \pm \\
0.5 \mathrm{~mm}\end{array}$ & $0.5 \mathrm{~mm}$ & $\begin{array}{l}0.0 \mathrm{~mm} \\
1.2 \mathrm{~mm}\end{array}$ & 6 & $\begin{array}{l}0.6 \mathrm{~mm} \pm \\
0.2 \mathrm{~mm}\end{array}$ & $0.6 \mathrm{~mm}$ & $\begin{array}{l}0.4 \mathrm{~mm} \\
0.9 \mathrm{~mm}\end{array}$ & 6 & $\begin{array}{l}0.5 \mathrm{~mm} \pm \\
0.4 \mathrm{~mm} \\
\end{array}$ & $0.3 \mathrm{~mm}$ & $\begin{array}{l}0.1 \mathrm{~mm} ; \\
1.0 \mathrm{~mm}\end{array}$ \\
\hline \multirow[t]{5}{*}{ Micro-CT } & $\begin{array}{l}\text { fBIC_buccal_ } \\
\mathrm{CT}\end{array}$ & 6 & $\begin{array}{l}2.3 \mathrm{~mm} \pm \\
1.7 \mathrm{~mm} \\
\end{array}$ & $2.7 \mathrm{~mm}$ & $\begin{array}{l}0.0 \mathrm{~mm} ; \\
4.5 \mathrm{~mm}\end{array}$ & 6 & $\begin{array}{l}3.1 \mathrm{~mm} \pm \\
0.6 \mathrm{~mm}\end{array}$ & $3.2 \mathrm{~mm}$ & $\begin{array}{l}2.2 \mathrm{~mm} \\
3.8 \mathrm{~mm}\end{array}$ & 5 & $\begin{array}{l}2.1 \mathrm{~mm} \pm \\
1.0 \mathrm{~mm}\end{array}$ & $2.0 \mathrm{~mm}$ & $\begin{array}{l}0.9 \mathrm{~mm} \\
3.5 \mathrm{~mm}\end{array}$ & 6 & $\begin{array}{l}3.1 \mathrm{~mm} \pm \\
0.8 \mathrm{~mm} \\
\end{array}$ & $3.0 \mathrm{~mm}$ & $\begin{array}{l}2.2 \mathrm{~mm} ; \\
4.0 \mathrm{~mm}\end{array}$ \\
\hline & $\begin{array}{l}\text { fBIC_lingual_ } \\
\mathrm{CT}\end{array}$ & 6 & $\begin{array}{l}1.0 \mathrm{~mm} \pm \\
1.6 \mathrm{~mm}\end{array}$ & $0.3 \mathrm{~mm}$ & $\begin{array}{l}0.0 \mathrm{~mm} ; \\
4.0 \mathrm{~mm}\end{array}$ & 6 & $\begin{array}{l}0.7 \mathrm{~mm} \pm \\
0.6 \mathrm{~mm}\end{array}$ & $0.6 \mathrm{~mm}$ & $\begin{array}{l}0.0 \mathrm{~mm} \\
1.5 \mathrm{~mm}\end{array}$ & 5 & $\begin{array}{l}1.3 \mathrm{~mm} \pm \\
0.6 \mathrm{~mm} \\
\end{array}$ & $1.4 \mathrm{~mm}$ & $\begin{array}{l}0.3 \mathrm{~mm} \\
1.8 \mathrm{~mm} \\
\end{array}$ & 6 & $\begin{array}{l}0.3 \mathrm{~mm} \pm \\
0.3 \mathrm{~mm} \\
\end{array}$ & $0.2 \mathrm{~mm}$ & $\begin{array}{l}0.0 \mathrm{~mm} ; \\
0.7 \mathrm{~mm}\end{array}$ \\
\hline & HT_O & 6 & $\begin{array}{l}0.2 \mathrm{~mm} \pm \\
0.3 \mathrm{~mm}\end{array}$ & $0.0 \mathrm{~mm}$ & $\begin{array}{l}0.0 \mathrm{~mm} \\
0.6 \mathrm{~mm}\end{array}$ & 6 & $\begin{array}{l}0.1 \mathrm{~mm} \pm \\
0.3 \mathrm{~mm} \\
\end{array}$ & $0.0 \mathrm{~mm}$ & $\begin{array}{l}0.0 \mathrm{~mm} ; \\
0.6 \mathrm{~mm}\end{array}$ & 5 & $\begin{array}{l}0.0 \mathrm{~mm} \pm \\
0.0 \mathrm{~mm}\end{array}$ & $0.0 \mathrm{~mm}$ & $\begin{array}{l}0.0 \mathrm{~mm} \\
0.0 \mathrm{~mm}\end{array}$ & 6 & $\begin{array}{l}0.0 \mathrm{~mm} \pm \\
0.0 \mathrm{~mm} \\
\end{array}$ & $0.0 \mathrm{~mm}$ & $\begin{array}{l}0.0 \mathrm{~mm} ; \\
0.0 \mathrm{~mm}\end{array}$ \\
\hline & HT_2 & 6 & $\begin{array}{l}1.5 \mathrm{~mm} \pm \\
0.8 \mathrm{~mm} \\
\end{array}$ & $1.8 \mathrm{~mm}$ & $\begin{array}{l}0.0 \mathrm{~mm} ; \\
2.2 \mathrm{~mm}\end{array}$ & 6 & $\begin{array}{l}1.2 \mathrm{~mm} \pm \\
0.8 \mathrm{~mm} \\
\end{array}$ & $1.3 \mathrm{~mm}$ & $\begin{array}{l}0.0 \mathrm{~mm} ; \\
2.1 \mathrm{~mm} \\
\end{array}$ & 5 & $\begin{array}{l}0.4 \mathrm{~mm} \pm \\
0.6 \mathrm{~mm} \\
\end{array}$ & $0.3 \mathrm{~mm}$ & $\begin{array}{l}0.0 \mathrm{~mm} ; \\
1.4 \mathrm{~mm} \\
\end{array}$ & 6 & \begin{tabular}{|l|}
$0.2 \mathrm{~mm} \pm$ \\
$0.3 \mathrm{~mm}$ \\
\end{tabular} & $0.2 \mathrm{~mm}$ & $\begin{array}{l}0.0 \mathrm{~mm} ; \\
0.6 \mathrm{~mm}\end{array}$ \\
\hline & HT_4 & 6 & $\begin{array}{l}1.7 \mathrm{~mm} \pm \\
0.3 \mathrm{~mm}\end{array}$ & $1.8 \mathrm{~mm}$ & $\begin{array}{l}1.4 \mathrm{~mm} \\
2.1 \mathrm{~mm}\end{array}$ & 6 & $\begin{array}{l}1.5 \mathrm{~mm} \pm \\
0.5 \mathrm{~mm}\end{array}$ & $1.5 \mathrm{~mm}$ & $\begin{array}{l}0.9 \mathrm{~mm} ; \\
2.1 \mathrm{~mm}\end{array}$ & 5 & $\begin{array}{l}1.4 \mathrm{~mm} \pm \\
0.5 \mathrm{~mm}\end{array}$ & $1.2 \mathrm{~mm}$ & $\begin{array}{l}1.0 \mathrm{~mm} \\
2.3 \mathrm{~mm}\end{array}$ & 6 & $\begin{array}{l}1.6 \mathrm{~mm} \pm \\
0.4 \mathrm{~mm}\end{array}$ & $1.5 \mathrm{~mm}$ & $\begin{array}{l}1.2 \mathrm{~mm} ; \\
2.3 \mathrm{~mm}\end{array}$ \\
\hline
\end{tabular}

Table 1 B

\begin{tabular}{|c|c|c|c|c|c|c|c|c|c|c|c|c|c|c|c|c|c|}
\hline \multirow{4}{*}{$\begin{array}{l}\text { Histo- } \\
\text { morpho- } \\
\text { metric }\end{array}$} & \multirow{3}{*}{$\begin{array}{l}\text { Variable } \\
\text { AA/TAA }\end{array}$} & \multicolumn{4}{|c|}{ PEG } & \multicolumn{4}{|c|}{ PEG-RGD } & \multicolumn{4}{|c|}{$\mathrm{CM}$} & \multicolumn{4}{|c|}{ empty } \\
\hline & & $\mathrm{n}$ & Mean \pm SD & Median & Min;Max & $\mathrm{n}$ & Mean \pm SD & Median & Min;Max & $\mathrm{n}$ & Mean \pm SD & Median & Min:Max & $\mathrm{n}$ & Mean \pm SD & Median & Min;Max \\
\hline & & 6 & $\begin{array}{l}37.1 \% \pm \\
5.6 \%\end{array}$ & $38.3 \%$ & $\begin{array}{l}27.2 \% \\
44.1 \%\end{array}$ & 6 & $\begin{array}{l}32.2 \% \pm \\
10.0 \%\end{array}$ & $31.2 \%$ & $\begin{array}{l}20.0 \% \\
50.0 \%\end{array}$ & 6 & $\begin{array}{l}39.7 \% \pm \\
10.1 \%\end{array}$ & $42.8 \%$ & $\begin{array}{l}21.6 \% ; \\
51.2 \%\end{array}$ & 5 & $\begin{array}{l}2.5 \% \pm \\
3.2 \%\end{array}$ & $1.1 \%$ & $\begin{array}{l}0.0 \% \\
8.1 \%\end{array}$ \\
\hline & $\begin{array}{l}\text { Newly formed } \\
\text { bone }\end{array}$ & 6 & $\begin{array}{l}9.6 \% \pm \\
6.6 \%\end{array}$ & $7.6 \%$ & $\begin{array}{l}3.9 \% \\
22.3 \%\end{array}$ & 6 & $\begin{array}{l}11.8 \% \pm \\
7.5 \%\end{array}$ & $9.7 \%$ & $\begin{array}{l}3.5 \% \\
25.5 \%\end{array}$ & 6 & $\begin{array}{l}16.7 \% \pm \\
3.7 \%\end{array}$ & $17.7 \%$ & $\begin{array}{l}11.0 \% ; \\
20.6 \%\end{array}$ & 5 & $\begin{array}{l}2.7 \% \pm \\
3.3 \%\end{array}$ & $1.3 \%$ & $\begin{array}{l}0.0 \% ; \\
8.3 \%\end{array}$ \\
\hline \multirow[t]{3}{*}{ analysis } & $\begin{array}{l}\text { Bone } \\
\text { substitute }\end{array}$ & 6 & $\begin{array}{l}14.1 \% \pm \\
6.4 \%\end{array}$ & $12.4 \%$ & $\begin{array}{l}8.7 \% \\
25.6 \%\end{array}$ & 6 & $\begin{array}{l}14.1 \% \pm \\
4.5 \%\end{array}$ & $12.3 \%$ & $\begin{array}{l}8.6 \% \\
20.6 \%\end{array}$ & 6 & $\begin{array}{l}12.0 \% \pm \\
4.5 \%\end{array}$ & $11.2 \%$ & $\begin{array}{l}8.0 \% \\
20.6 \%\end{array}$ & 5 & $\begin{array}{l}0.0 \% \pm \\
0.0 \%\end{array}$ & $0.0 \%$ & $\begin{array}{l}0.0 \% ; \\
0.0 \%\end{array}$ \\
\hline & fBIC_buccal & 6 & $\begin{array}{l}2.1 \mathrm{~mm} \pm \\
1.6 \mathrm{~mm}\end{array}$ & $2.5 \mathrm{~mm}$ & $\begin{array}{l}0.0 \mathrm{~mm} ; \\
3.8 \mathrm{~mm}\end{array}$ & 6 & $\begin{array}{l}2.4 \mathrm{~mm} \pm \\
1.5 \mathrm{~mm}\end{array}$ & $3.1 \mathrm{~mm}$ & $\begin{array}{l}0.2 \mathrm{~mm} ; \\
3.8 \mathrm{~mm}\end{array}$ & 6 & $\begin{array}{l}2.5 \mathrm{~mm} \pm \\
0.9 \mathrm{~mm}\end{array}$ & $3.0 \mathrm{~mm}$ & $\begin{array}{l}1.0 \mathrm{~mm} ; \\
3.3 \mathrm{~mm}\end{array}$ & 6 & $\begin{array}{l}3.5 \mathrm{~mm} \pm \\
1.2 \mathrm{~mm}\end{array}$ & $3.8 \mathrm{~mm}$ & $\begin{array}{l}1.4 \mathrm{~mm} ; \\
4.8 \mathrm{~mm}\end{array}$ \\
\hline & fBIC_lingual & 6 & $\begin{array}{l}0.1 \mathrm{~mm} \pm \\
0.1 \mathrm{~mm}\end{array}$ & $0.0 \mathrm{~mm}$ & $\begin{array}{l}0.0 \mathrm{~mm} ; \\
0.3 \mathrm{~mm}\end{array}$ & 6 & $\begin{array}{l}0.4 \mathrm{~mm} \pm \\
0.6 \mathrm{~mm}\end{array}$ & $0.1 \mathrm{~mm}$ & $\begin{array}{l}0.0 \mathrm{~mm} ; \\
1.4 \mathrm{~mm}\end{array}$ & 6 & $\begin{array}{l}0.5 \mathrm{~mm} \pm \\
0.4 \mathrm{~mm}\end{array}$ & $0.6 \mathrm{~mm}$ & $\begin{array}{l}0.0 \mathrm{~mm} ; \\
0.9 \mathrm{~mm}\end{array}$ & 6 & $\begin{array}{l}0.3 \mathrm{~mm} \pm \\
0.4 \mathrm{~mm}\end{array}$ & $0.2 \mathrm{~mm}$ & $\begin{array}{l}0.0 \mathrm{~mm} ; \\
0.9 \mathrm{~mm}\end{array}$ \\
\hline \multirow[t]{3}{*}{ Micro-CT } & $\begin{array}{l}\text { fBIC_buccal_ } \\
\mathrm{CT}\end{array}$ & 5 & $\begin{array}{l}2.2 \mathrm{~mm} \pm \\
0.9 \mathrm{~mm}\end{array}$ & $2.0 \mathrm{~mm}$ & $\begin{array}{l}0.9 \mathrm{~mm} ; \\
3.1 \mathrm{~mm}\end{array}$ & 5 & $\begin{array}{l}2.0 \mathrm{~mm} \pm \\
1.1 \mathrm{~mm}\end{array}$ & $2.0 \mathrm{~mm}$ & $\begin{array}{l}0.5 \mathrm{~mm} ; \\
3.1 \mathrm{~mm}\end{array}$ & 6 & $\begin{array}{l}1.5 \mathrm{~mm} \pm \\
1.3 \mathrm{~mm}\end{array}$ & $1.0 \mathrm{~mm}$ & $\begin{array}{l}0.5 \mathrm{~mm} ; \\
4.0 \mathrm{~mm}\end{array}$ & 6 & $\begin{array}{l}3.2 \mathrm{~mm} \pm \\
1.3 \mathrm{~mm}\end{array}$ & $3.5 \mathrm{~mm}$ & $\begin{array}{l}1.0 \mathrm{~mm} ; \\
4.4 \mathrm{~mm}\end{array}$ \\
\hline & HT_2 & 5 & $\begin{array}{l}0.4 \mathrm{~mm} \pm \\
0.5 \mathrm{~mm}\end{array}$ & $0.1 \mathrm{~mm}$ & $\begin{array}{l}0.0 \mathrm{~mm} \\
1.1 \mathrm{~mm}\end{array}$ & 5 & $\begin{array}{l}0.4 \mathrm{~mm} \pm \\
0.4 \mathrm{~mm}\end{array}$ & $0.5 \mathrm{~mm}$ & $\begin{array}{l}0.0 \mathrm{~mm} ; \\
0.9 \mathrm{~mm}\end{array}$ & 6 & $\begin{array}{l}0.7 \mathrm{~mm} \pm \\
0.5 \mathrm{~mm}\end{array}$ & $0.8 \mathrm{~mm}$ & $\begin{array}{l}0.0 \mathrm{~mm} ; \\
1.3 \mathrm{~mm}\end{array}$ & 6 & $\begin{array}{l}0.2 \mathrm{~mm} \pm \\
0.5 \mathrm{~mm}\end{array}$ & $0.0 \mathrm{~mm}$ & $\begin{array}{l}0.0 \mathrm{~mm} \\
1.1 \mathrm{~mm}\end{array}$ \\
\hline & HT_4 & 5 & $\begin{array}{l}1.6 \mathrm{~mm} \pm \\
0.6 \mathrm{~mm}\end{array}$ & $1.8 \mathrm{~mm}$ & $\begin{array}{l}0.9 \mathrm{~mm} ; \\
2.3 \mathrm{~mm}\end{array}$ & 5 & $\begin{array}{l}1.4 \mathrm{~mm} \pm \\
0.6 \mathrm{~mm}\end{array}$ & $1.2 \mathrm{~mm}$ & $\begin{array}{l}0.7 \mathrm{~mm} ; \\
2.2 \mathrm{~mm}\end{array}$ & 6 & $\begin{array}{l}1.5 \mathrm{~mm} \pm \\
0.9 \mathrm{~mm}\end{array}$ & $1.6 \mathrm{~mm}$ & $\begin{array}{l}0.3 \mathrm{~mm} ; \\
2.6 \mathrm{~mm}\end{array}$ & 6 & $\begin{array}{l}0.6 \mathrm{~mm} \pm \\
0.6 \mathrm{~mm}\end{array}$ & $0.5 \mathrm{~mm}$ & $\begin{array}{l}0.0 \mathrm{~mm} ; \\
1.6 \mathrm{~mm}\end{array}$ \\
\hline
\end{tabular}




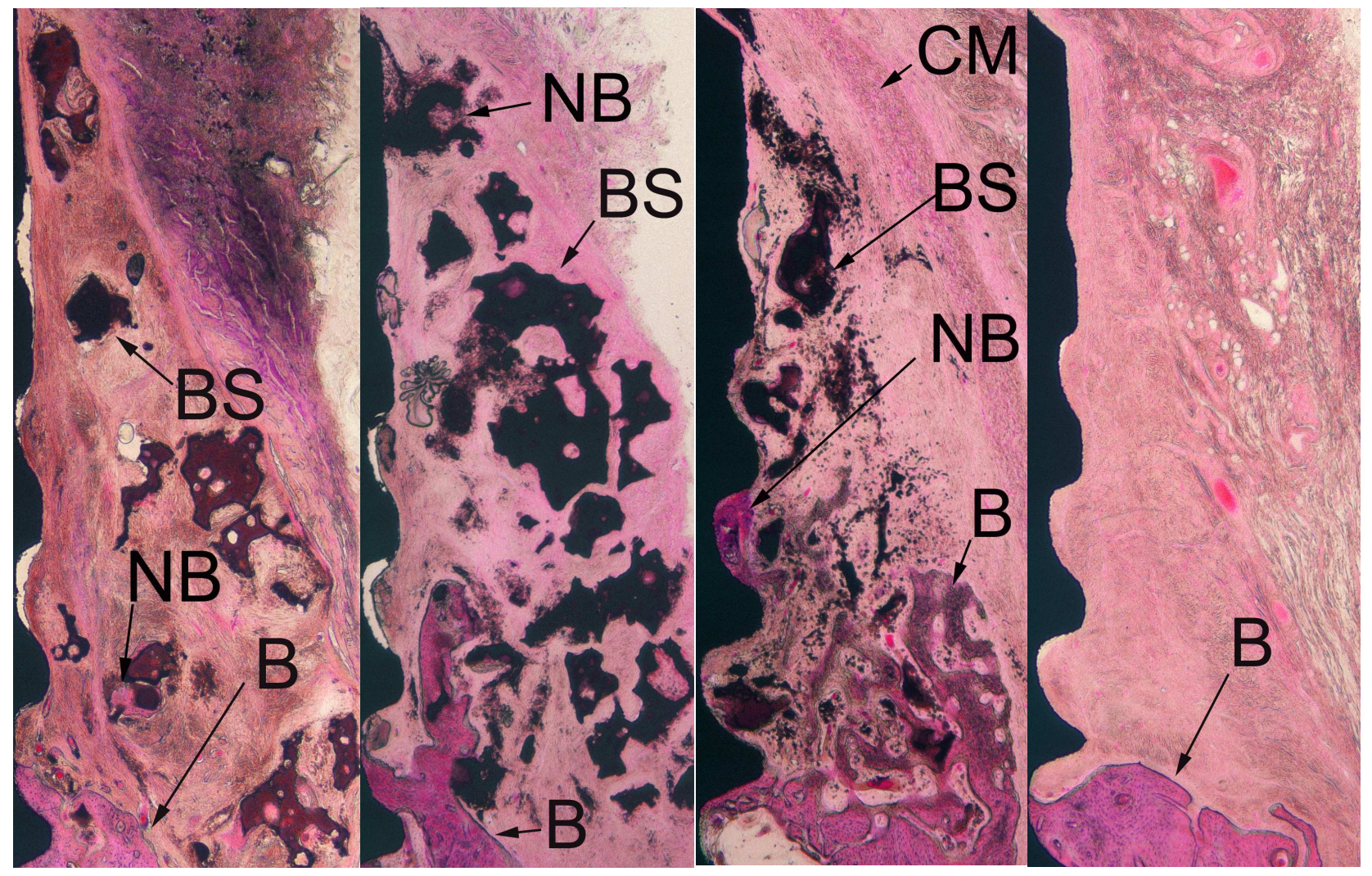

Figure 4a-d

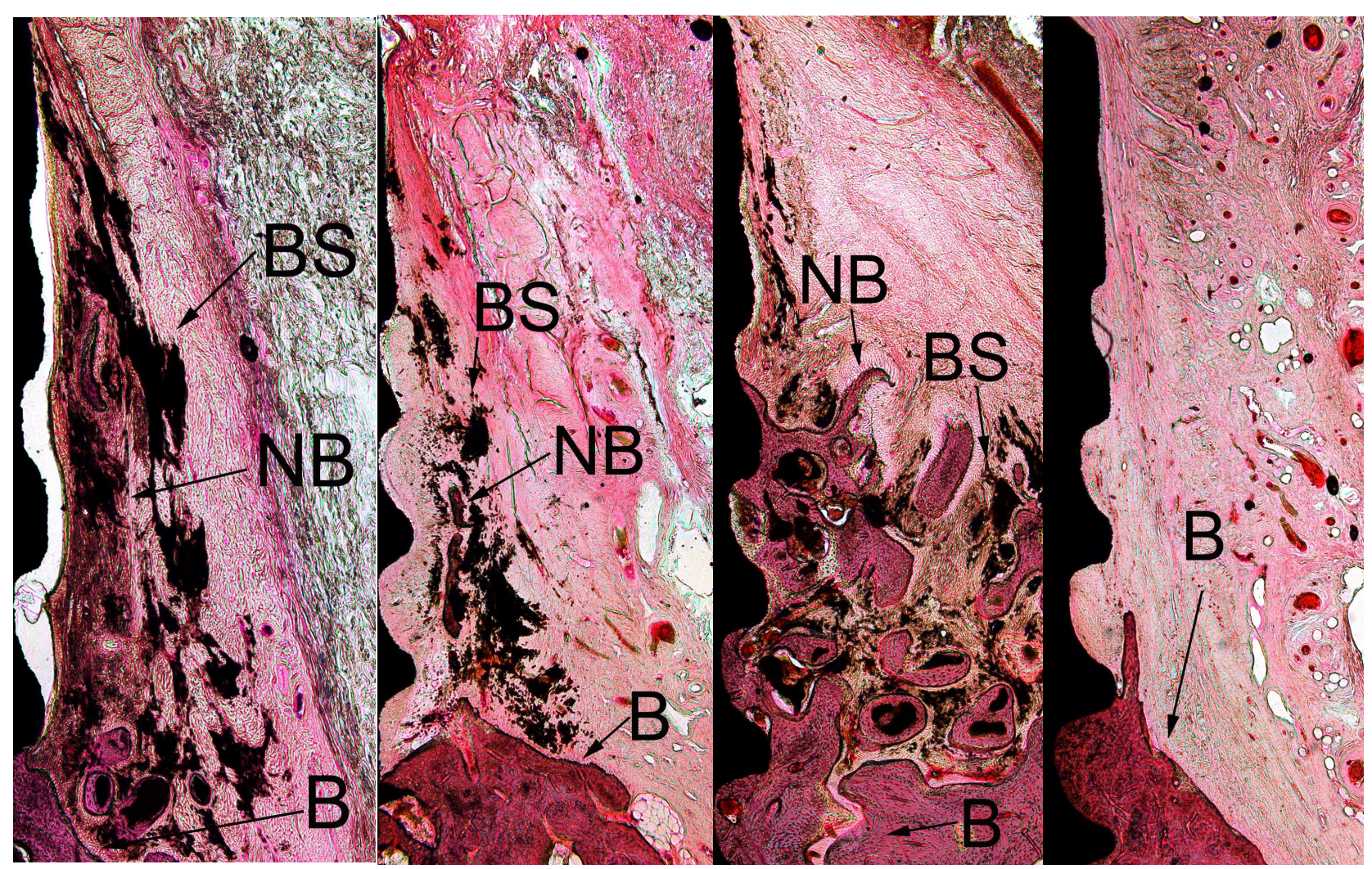

Figure 5a-d 